\title{
Highly Deformable Energy-Dissipating Reinforced Concrete Elements in Seismic Design of Reinforced Concrete Structures
}

\author{
Momoh Emmanuel Owoichoechi*, Kypros Pilakoutas** \\ *(Department of Civil Engineeering, University of Agriculture, Makurdi, Nigeria, West Africa \\ Email: momohemmanuel85@gmail.com) \\ ** (Department of Civil and Structural Engineering, The University of Sheffield, United Kingdom \\ Email: k.pilakoutas@sheffield.ac.uk)
}

\begin{abstract}
Incorporating scrap tyre rubber particles as partial replacement for aggregates has been found to produce concrete with improved ductility, deformability and damping which are desired characteristics of a viable material for enhancing structural response to earthquake vibrations. An analytical study using Drain-2dX was carried out to investigate the response of 4-storey, 3-bay reinforced concrete frames on innovative rubberised concrete deformable foundation models to simulated earthquake scaled to 5 different peak ground accelerations. Stress-strain properties of 3-layers aramid fibre-reinforced polymer (FRP)-confinement for concrete incorporating waste rubber from scrap vehicle tyres were used to model the elements of this foundation models. With a partial decoupling of the superstructure from the direct earthquake force, the models showed up to $70 \%$ reduction in base shear, an improved overall q-factor of 7.1, and an estimated frame acceleration of $0.11 \mathrm{~g}$ for an earthquake peak ground acceleration of $0.44 \mathrm{~g}$. This implies that a non-seismically designed reinforced concrete frame on the proposed rubberised concrete deformable foundation system would provide a simple, affordable and equally efficient alternative to the conventional and usually expensive earthquake resistant concrete frames. A supplementary Arrest System (SAS) was proposed to anchor the frame from the resulting soft storey at the rubberised concrete foundation. A further research is recommended for the design of concrete hinges with rubberised concrete as used in the model with the most impressive response.
\end{abstract}

Keywords: Rubberised, Deformable, Scrap tyre, Fibre-reinforced polymer-confined reinforced rubberized concrete (FRPCRRC), Peak ground acceleration.

\section{INTRODUCTION}

A building designed for earthquake resistance is a structural system which basically provides safety and protection for lives and properties, limits the extent of damage on the structure itself and which ensures the continuity of essential services for people-safety during and after the occurrence of a reference earthquake event [1].

Modern seismic design emphasizes ductility for structural elements. In other words, post-elastic behaviour should be allowed in structural response to some severe reference earthquake. The advantages of ductile design include: ductile response of the structure which as well implies energy dissipation, damping of structural response, reduced seismic forces, safety against collapse, and economy in design. In an attempt to achieve ductility in reinforced concrete structures designed for earthquake resistance, guidelines for special detailing of steel reinforcement have been provided in seismic design codes (e.g. EN1998-1:2004). However, for conventional reinforced concrete, the achieved ductility is capped at a limit due to inherent brittleness of concrete usually accompanied with sudden failure. Most fatalities resulting from earthquake disasters are a direct result of the quality of buildings [2]. These poor quality buildings are so brittle and fall on their occupants at the slightest shaking. [3] noted that the world population is projected to double in about 50 years and the implication of this is that about 1 billion additional housing units are needed to meet the housing needs of mankind. This is aside the fact that there is already a dire need for housing all over developing countries. The author further reported that about $68 \%$ of the 79 most populated cities in seismically active regions of the world are located in developing countries. Due to increasing population, there is more pressure for erection of buildings which are often poorly constructed.

From a societal stand-point, the current increase in population growth rate and consequent need for safe shelter in earthquake prone regions with a continued state of civil unrest and social instability greatly necessitates providing concrete that is cheap and possesses enhanced dynamic properties together with simple construction techniques. This necessitated recent developments in 
FRP confinement of rubberized concrete to negate strength loss. As a result, a cheap, more ductile and deformable concrete, suitable for structural application in seismically active zones is then achievable [4], [5], [6], [7], [8] and [9].

The current research aims at enhancing seismic resistance of buildings through simple models and techniques with the use of highly deformable energy-dissipating reinforced concrete elements made of FRP-confined reinforced rubberised concrete.

\section{METHODOLOGY}

\subsection{Frame Description and Modeling}

In base isolation of structures for earthquake resistance, the goal is to use a deformable system to create a soft storey at the base of the building such that the superstructure is protected from the direct impact of the seismic force [10], [11] and [12]. Similarly, introducing some deformability and damping by the use of rubberised concrete at the foundation level will reduce the force demand on the global frame. Hence, foundation models (Models A, B, C and D) were designed, tested and assessed under an artificial earthquake with the aid of Drain-2dX software. The models are shown in Figs 2-9. These were assessed and compared with the control model which is a 4storey, 3-bay reinforced concrete frame designed according to the requirements of EC-8.

All analytical models had an extended floor height of $1.5 \mathrm{~m}$ below ground level. The extended portion of the foundation is made up of the column footings with each column having FRPCRRC wing beams, ground beam and supporting FRPCRRC short columns. The connections between the column bases and the foundation are modelled as rollers and the floor beam is modelled as a diaphragm. Model C and $\mathrm{D}$ are the same except that for model $\mathrm{D}$, the FRPCRRC foundation columns are supported on to the foundation as concrete hinges. The foundation elements of all models have the stress-strain property of FRP-confined rubberised concrete columns as shown in Fig 1.

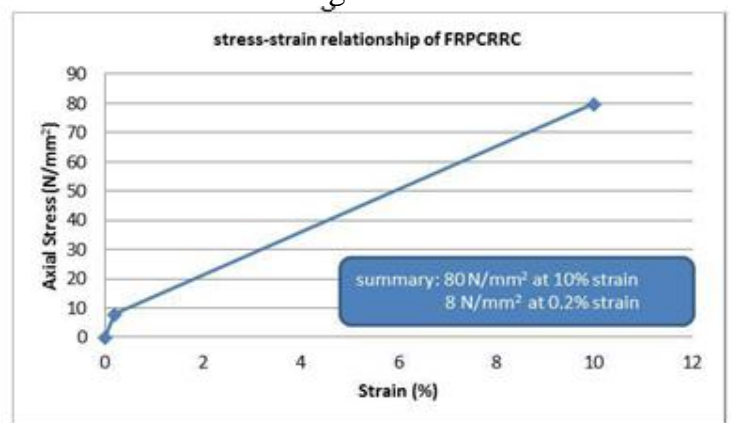

Fig 1: Stress-strain properties of FRP-confined rubberised concrete $(60 \%$ crumb rubber) confined with 3 layers of Aramid Fabric [13]

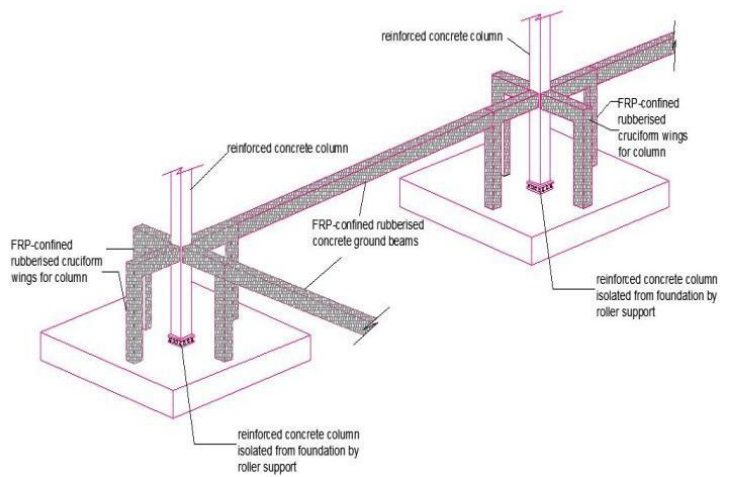

Fig 2: Pictorial representation of the deformable foundation system for model A

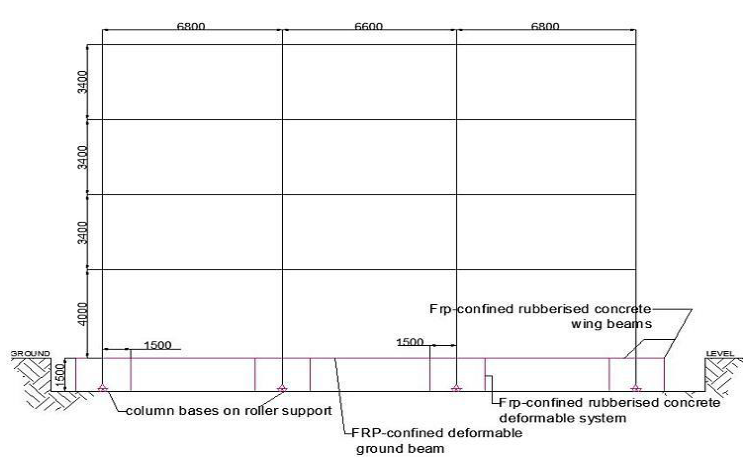

Fig 3: Two-dimmensional representation of the deformable foundation system for model A

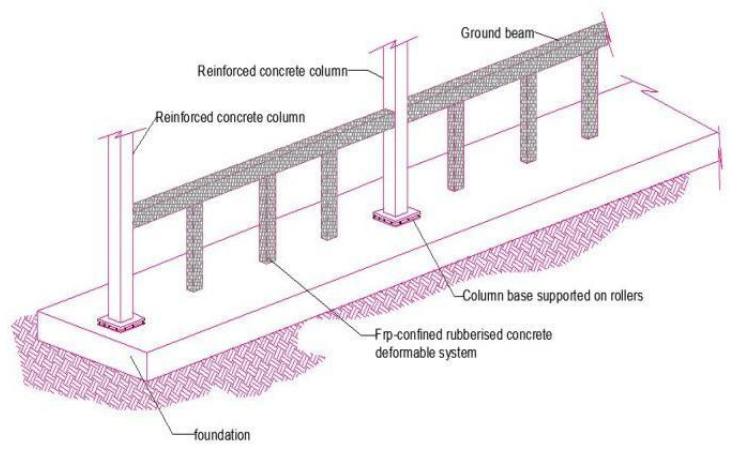

Fig 4: Pictorial representation of the deformable foundation system for model B

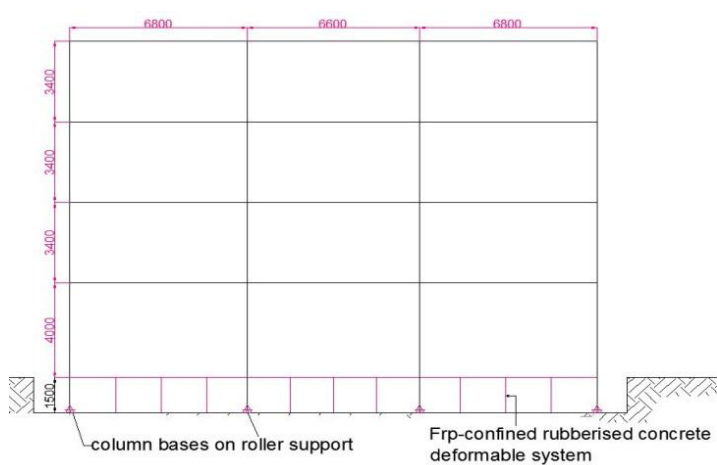

Fig 5: A 2-D representation of the deformable foundation system for model B 


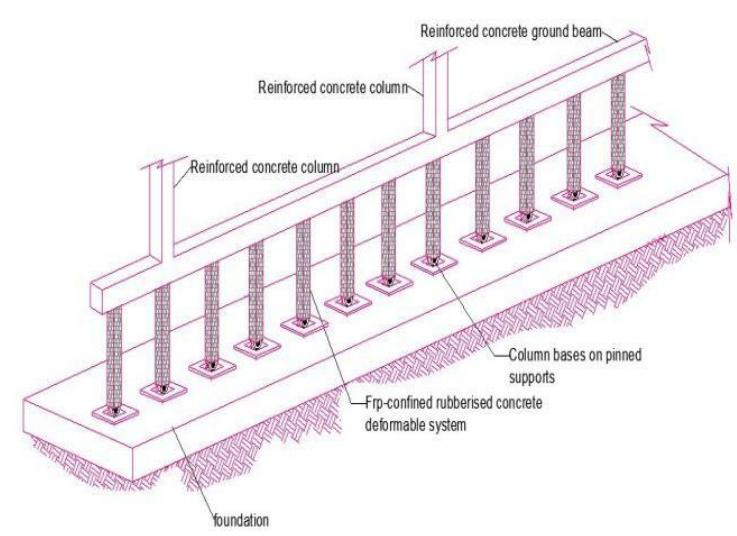

Fig 8: Pictorial representation of the deformable foundation system for model D

The philosophy behind these foundation systems is that gravity load is borne by the frame while lateral excitation is borne by the deformable system of sup-porting short columns and ground beams. Properties of the constituting materials of the deformable foundation system are shown as follows: - Compressive strength FRPCRRC, fc $=80 \mathrm{~N} / \mathrm{mm} 2$

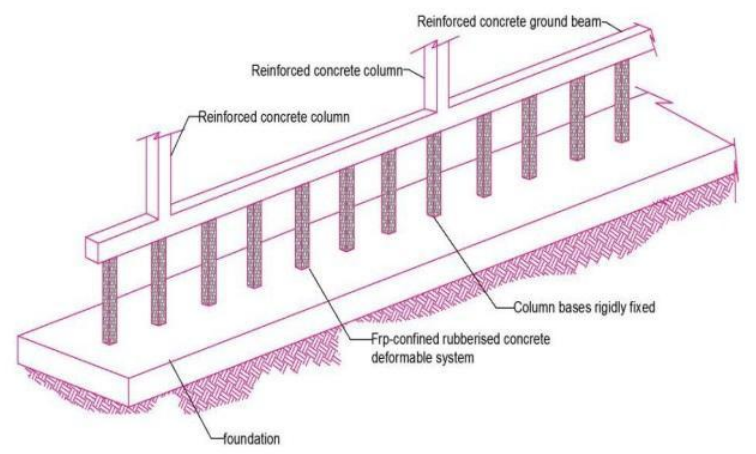

Fig 6: Pictorial representation of the deformable foundation system for model $\mathrm{C}$

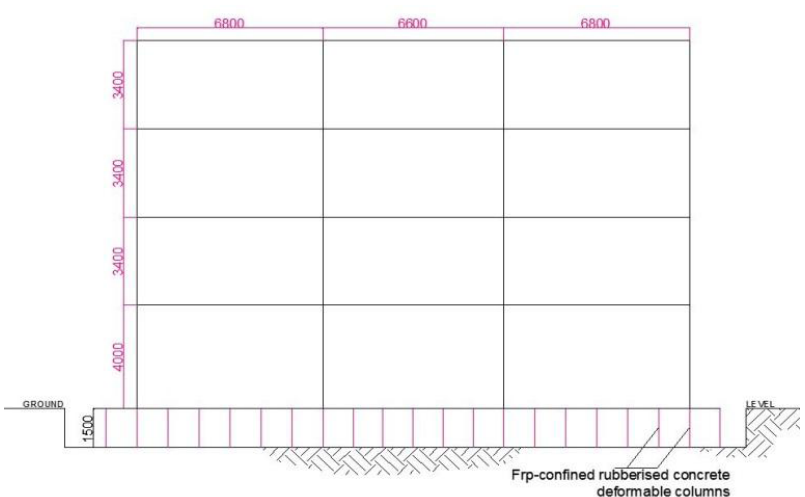

Fig 7: A 2-D representation of the deformable foundation system for model C

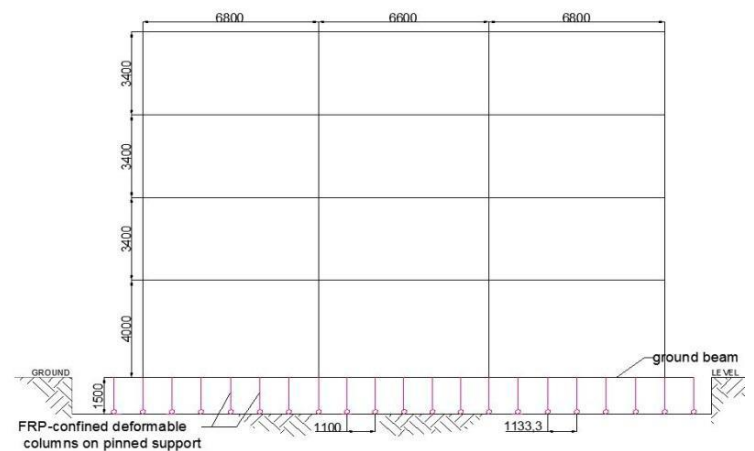

Fig 9: 2-D representation of the deformable foundation system for model $\mathrm{D}$

- Maximum strain of FRPCRRC $=0.100$

- Modulus of Elasticity E $=400 \mathrm{~N} / \mathrm{mm} 2$

- Ratio of final stiffness to initial stiffness of the above concrete $\mathrm{k}_{2} / \mathrm{k}_{1}=20 \%$

These properties were obtained from stressstrain experiments of $150 \mathrm{~mm} \times 300 \mathrm{~mm}$ cylindrical rubberised concrete elements confined with 3 layers of aramid fibres by [13]. For the structural design of these models, the following steel properties were used:

- Steel reinforcement fy $=250 \mathrm{~N} / \mathrm{mm} 2$

- Steel yield strain $\mathrm{fy}=0.00109$

\section{RESULTS AND DISCUSSION}

\subsection{Linear Elastic Response Spectrum Analysis}

Linear elastic multi-modal response analysis was carried out to determine the modal properties and force demands on the various elements of the structure. The various sections were then designed and the section resistances were assigned in the software for the non-linear dynamic time history analysis. Table 1 presents periods and effective modal masses of the models. The incorporation of a deformable concrete system at the foundation improved the ductility of the structure. Increases in periods of vibration, implies that structural response is to the right side of the earthquake spectrum. The more to the right the structure's period is pushed, the lesser the acceleration of the structure and consequently a reduction of the force demand from the reference earthquake. Models $\mathrm{A}$ and $\mathrm{D}$ have the longest periods.

\subsection{Non Linear Dynamic Time-history Analysis}

A comparison in the base shear and maximum roof drifts for the 5 frame models is displayed in Table 2. Comparison of base shear force for the models show an increase in base shear with increase in the seismic force. Interestingly, the base shears for the frame models on FRPCRRC deformable foundation system are significantly 
lower as expected. Model D displays up to $70 \%$ reduction in the base shear demand on the structure. The factors responsible for this desired structural response include:

- Increased redundancy of the frames due to extra load paths provided by the FRPCRRC deformable foundation system;

- Increased ductility due to the highly deformable property of the rubberised concrete leading to an improved non-linear ductile response;

- Increased energy dissipation through rotation and flexure which concentrated damage on the foundation system and
- Partial Isolation of the superstructure from the direct impact of the seismic force as was observed in the response of Model D

From a quick and approximate approach, Newton's second law states that; $\mathrm{a}=\mathrm{F} / \mathrm{m}$

Mass of Control Frame $=437,000.0 \mathrm{~kg}$

Mass of FRPCRRC foundation $=17,546.0 \mathrm{~kg}$

Total mass of Model $(\mathrm{C}$ or D) $=454,546.0 \mathrm{~kg}$ $\mathrm{a}=1.122 \mathrm{~m} / \mathrm{s} 2$ or $0.11 \mathrm{~g}$

Expressing the acceleration in terms of $g$ gives a peak ground acceleration of $0.11 \mathrm{~g}$ which implies that a conventional non-seismically designed frame supported on this deformable foundation system will be safe against high magnitude earthquakes.

Table 1: Periods and Effective Modal Masses of Models

\begin{tabular}{|c|c|c|c|c|c|}
\hline \multirow{2}{*}{$\begin{array}{l}\text { CONTROL } \\
\text { FRAME }\end{array}$} & \multicolumn{5}{|c|}{ Vibration Mode } \\
\hline & 1 & 2 & 3 & 4 & 5 \\
\hline Period (s) & 1.1537 & 0.3687 & 0.2096 & 0.1492 & - \\
\hline Effective Modal Mass (\%) & 89.30 & 8.36 & 1.95 & 0.38 & - \\
\hline \multicolumn{6}{|l|}{ MODEL A } \\
\hline Period (s) & 1.8272 & 0.5038 & 0.2626 & 0.1780 & 0.090 \\
\hline Effective Modal Mass (\%) & 95.40 & 2.98 & 0.42 & 0.08 & 1.12 \\
\hline \multicolumn{6}{|l|}{ MODEL B } \\
\hline Period (s) & 1.6123 & 0.4345 & 0.2254 & 0.1525 & 2.08 \\
\hline Effective Modal Mass (\%) & 94.71 & 2.71 & 0.41 & 0.09 & 2.08 \\
\hline \multicolumn{6}{|l|}{ MODEL C } \\
\hline Period (s) & 1.3856 & 0.4199 & 0.2261 & 0.1540 & 0.1074 \\
\hline Effective Modal Mass (\%) & 92.42 & 5.23 & 0.90 & 0.24 & 1.20 \\
\hline \multicolumn{6}{|l|}{ MODEL D } \\
\hline Period (s) & 1.800 & 0.4709 & 0.2405 & 0.1609 & 0.1304 \\
\hline Effective Modal Mass (\%) & 97.52 & 2.02 & 0.03 & 0.09 & 0.12 \\
\hline
\end{tabular}

Table 2. Comparison of Base Shear for the Frame Models

\begin{tabular}{|c|c|c|c|c|c|c|}
\hline PGA & Parameter & $\begin{array}{l}\text { CONTROL } \\
\text { FRAME }\end{array}$ & $\begin{array}{c}\text { MODEL } \\
\text { A }\end{array}$ & $\begin{array}{c}\text { MODEL } \\
\text { B }\end{array}$ & $\begin{array}{c}\text { MODEL } \\
\text { C }\end{array}$ & $\begin{array}{c}\text { MODEL } \\
\text { D }\end{array}$ \\
\hline \multirow{3}{*}{$0.28 \mathrm{~g}$} & Base Shear Force $(\mathrm{kN})$ & 1210 & 920 & 530 & 600 & 360 \\
\hline & Maximum Roof drift $(\mathrm{cm})$ & 13.6 & 17.6 & 16.3 & 11.3 & 14.5 \\
\hline & Percentage reduction of Base Shear (\%) & - & 24 & 56 & 50 & 70.2 \\
\hline \multirow{3}{*}{$0.30 \mathrm{~g}$} & Base Shear Force $(\mathrm{kN})$ & 1240 & 880 & 600 & 630 & 380 \\
\hline & Maximum Roof drift $(\mathrm{cm})$ & 14.4 & 18.5 & 17.5 & 12.4 & 15.5 \\
\hline & Percentage reduction of Base Shear (\%) & - & 29 & 52 & 49 & 69.4 \\
\hline \multirow{3}{*}{$0.34 \mathrm{~g}$} & Base Shear Force $(\mathrm{kN})$ & 1350 & 960 & 650 & 708 & 420 \\
\hline & Maximum Roof drift $(\mathrm{cm})$ & 16.0 & 20.1 & 19.2 & 14.6 & 17.6 \\
\hline & Percentage reduction of Base Shear (\%) & - & 29 & 52 & 48 & 69.0 \\
\hline \multirow{3}{*}{$0.40 \mathrm{~g}$} & Base Shear Force $(\mathrm{kN})$ & 1450 & 1050 & 700 & 850 & 470 \\
\hline & Maximum Roof drift $(\mathrm{cm})$ & 17.7 & 22.5 & 21.7 & 18 & 20.7 \\
\hline & Percentage reduction of Base Shear (\%) & - & 28 & 52 & 41 & 67.5 \\
\hline \multirow{3}{*}{$0.44 \mathrm{~g}$} & Base Shear Force $(\mathrm{kN})$ & 1530 & 1140 & 750 & 950 & 510 \\
\hline & Maximum Roof drift $(\mathrm{cm})$ & 19.3 & 23.6 & 22.5 & 20.4 & 22.7 \\
\hline & Percentage reduction of Base Shear (\%) & - & 26 & 51 & 38 & 66.7 \\
\hline
\end{tabular}


The reduced acceleration also provides a quick estimate of the cost effectiveness of providing extra amount of material for the foundation (among which cheap waste tyre constitute a significant volume). In other words, expending an extra $4 \%$ of the cost of the building on this special foundation system reduces the seismic demand on the building by $65-70 \%$. Furthermore, less demand on the frame implies that such frame can be designed according the provisions of EN1992 and the savings in construction cost channeled towards the provision of these deformable foundation systems. Then reduction in cost from replacing a frame designed according to EN1998 with one designed according to the provisions of EN1992 negates possible extra costs needed for an FRPCRRC foundation. It then becomes possible to provide deformable foundations systems that are not only cost-effective but display superior structural response.

\subsubsection{Damage in Structure}

A study of the formation of plastic hinges reveals that the frames on FRPCRRC deformable foundation systems showed less damage. Fig 10 shows the level of damage for each frame model at peak ground acceleration of $0.4 \mathrm{~g}$. The red dots on the frames represent plastic hinges. Generally, the analytical models showed less damage since there was a reduction in the demand on the frames.
Damage was concentrated on the deformable foundation elements which is in fact the intended structural behaviour for the models. It is evident that Model D has the most superior structural response as it showed no damage on the frame. Reduction in seismic demands on Models A and B were due to increased ductility and energy dissipation while Models C and D responded like base isolation systems and deflected the seismic forces directed at the frame. The observation on energy dissipation reveals these modes of structural response for the frames.

\subsection{Practical Implications for Construction Considerations}

Isolating a column base from its bearing pad may seem to be a formidable attempt alongside the extra cost implications involved. A practical and less expensive option will be to create an oversized square depression in the bearing foundation pad, placing a steel plate of appropriate thickness that matches the plan dimension of the square depression, placing steel ball bearings on the steel plate, and then placing another steel plate on the top of the ball bearings. This top steel plate then act as an end cap for the reinforced concrete column base. The over-sized plan dimension of the depressed area of the foundation base allows for the differential lateral displacement of the column base. Due to time
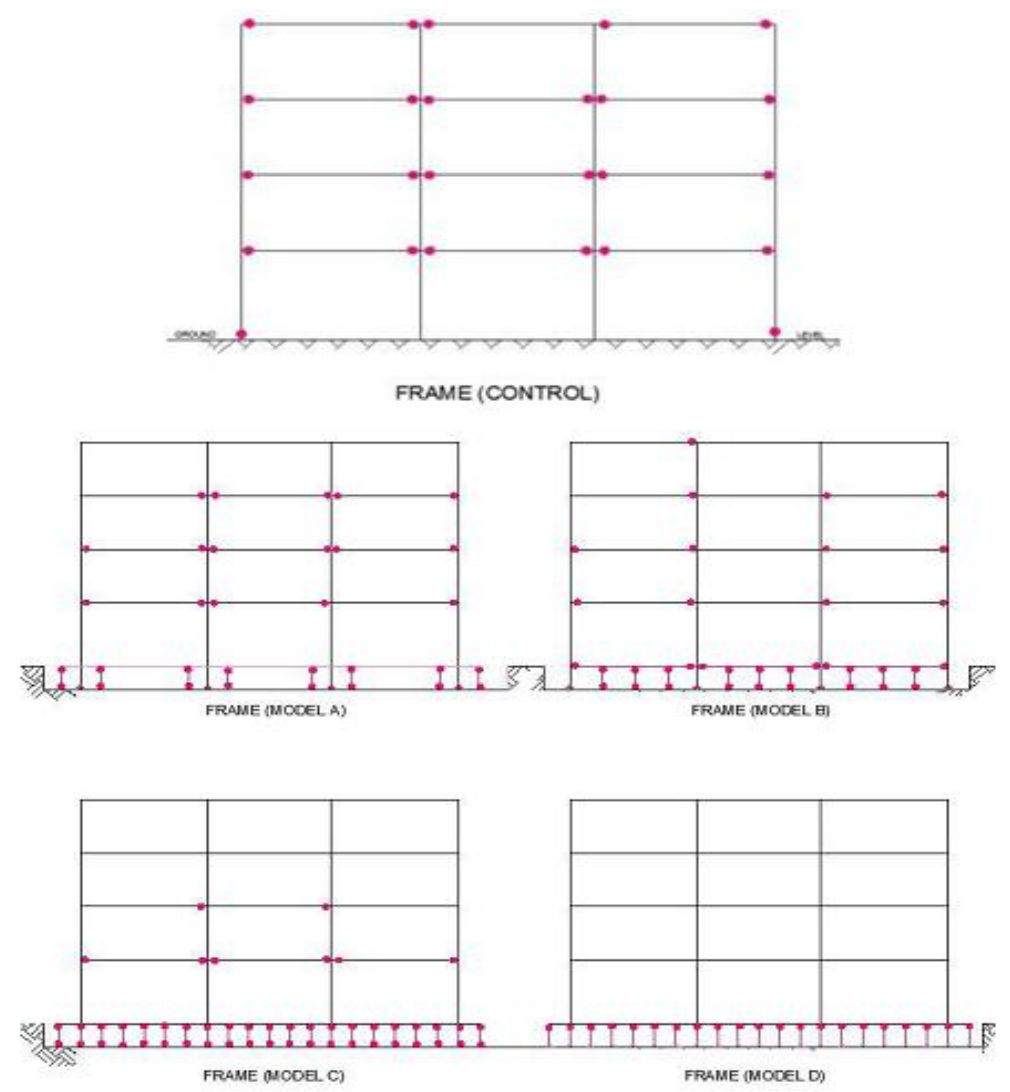

Fig 10: Comparison of Plastic hinges formation in Frames at 0.40g PGA 
constraint, analysis and design of this foundation system has been scheduled for future work on this research.

Another factor to be considered in the feasibility of models $\mathrm{C}$ and $\mathrm{D}$ is the provision of a supplementary arrest system (SAS) that will anchor the superstructure, should the earthquake force exceed the resistances of the FRPCRRC deformable foundation elements. Due to the high deformability of these elements, a soft storey was formed during the structure's response to ground motion and it becomes necessary to provide a simple supplementary restore system. Fig 11 shows a sketch of an innovative, practical and less technically involving arrest system for the structure. This system could either be made of either steel or reinforced concrete or composite. It has the shape of an inverted-V with the top accommodating a steel plate in its depression such that steel ball bearings are borne in-between it and a similar steel plate under the ground beam. The bases of the supplementary arrest system should be designed such that they are connected to the foundation by rigid supports. It is important to note that the inverted-V restore system is rigidly fixed to the foundation while the bases of the FRPCRRC deformable elements are connected on to the foundation by a mesnager type hinge support.

\section{CONCLUSION}

For the provision of highly deformable, energy-dissipating reinforced concrete elements, FRP-confined reinforced rubberised concrete (FRPCRRC) has proven to be an efficient material in improving structural response to earthquakes. The following conclusions are therefore made: FRPCRRC elements incorporated in the foundation of reinforced concrete frames can reduce base shear demand by $70 \%$. Acceleration demand on a building can be reduced by $75 \%$, the implication of which is that, the smaller frequent earthquakes will leave no damage on the structure.

Only about $4 \%$ of the total materials needed for a Eurocode- 8 frame amounts to the extra cost needed for an FRPCRRC deformable foundation system. The reduction in demand implies less material for the superstructure. The reduction of materials from the superstructure negates cost increases associated with the cost requirement of the FRPCRRC foundation. The proposed deformable system made from FRP-confined rubberised concrete is simple to construct, easy to model, will not be affected by ageing since the constituents are non-biodegradable, therefore providing a costeffective solution for poor communities in earthquake-prone areas. Scrap rubber from waste tyre is cheap. Incorporating it in concrete will not only enhance seismic response of concrete structures but will also greatly reduce the environmental problems caused by waste tyres disposal. The stress-strain relationship of rubberised concrete used for this research is that of circular cross-section whereas all the deformable concrete elements were designed as square cross-section. Although the effect of this may not be significant, it is better that a further study takes this into consideration in order to reduce the assumptions in modelling.

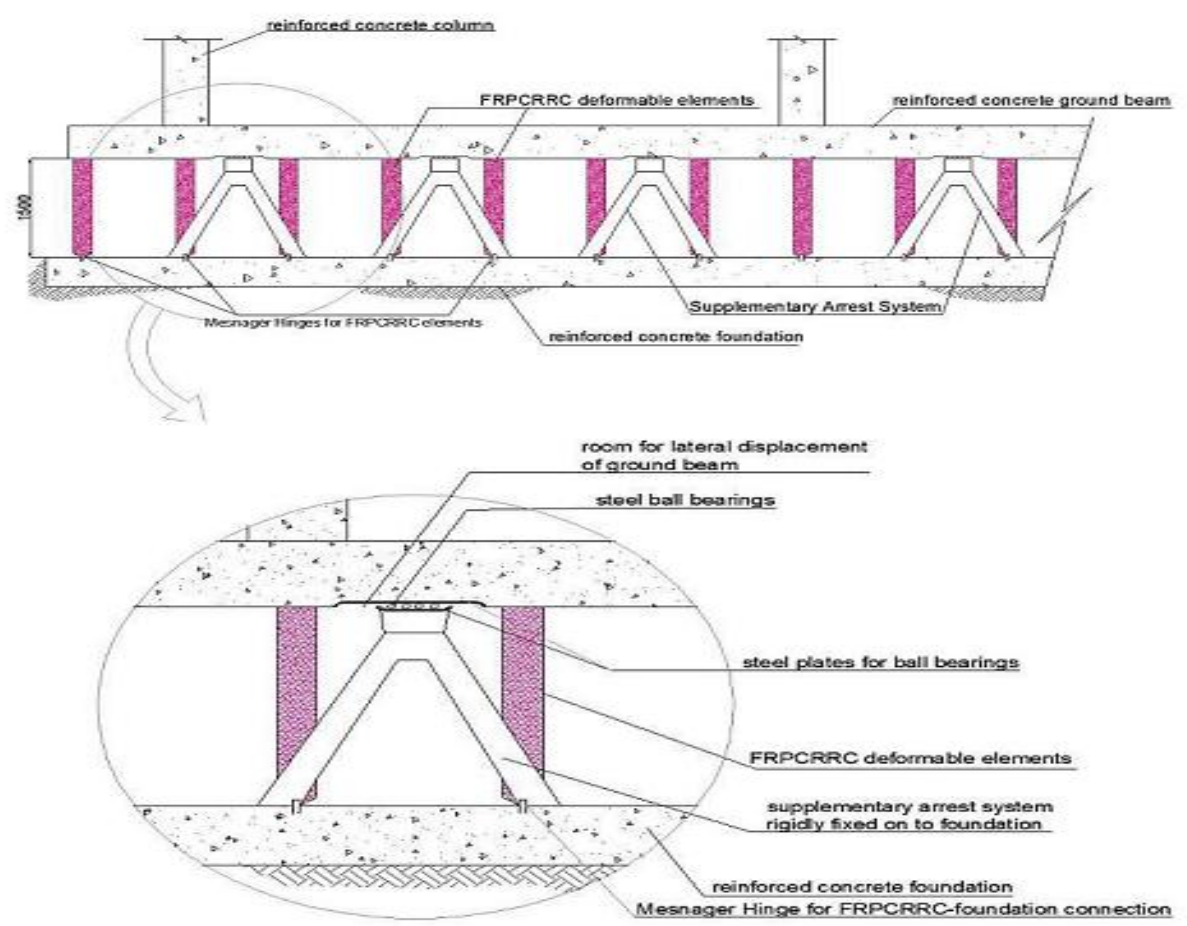

Fig 11: Proposed supplementary arrest system (SAS) for models $C$ and D 
There is the possibility that rubberised concrete will consolidate under sustained load for a long duration of time and may become less deformable. Further studies should be carried out to study this suspected time-dependent behaviour. Shake table tests are needed to validate the findings of this research. The DRAIN-2dX software used for the research was not equipped with a post-processor which made the manual procedure of processing huge files of data very strenuous and time consuming.

Due to time constraints, only one earthquake time history was used in this research to investigate structural response. Further investigation needs to be carried out using a good number of recorded earthquake time histories.

\section{ACKNOWLEDGEMENTS}

Our sincere thanks go to the University of Agriculture Makurdi, Nigeria for providing sponsorship for this research.

\section{REFERENCES}

[1]. Englerkirk R. E., seismic design of reinforced and precast concrete buildings. (Library of Congress. John Wiley and Sons Inc, Hoboken, New Jersey, 2003) 7-30.

[2]. Penelis, G. P. and A. J. Kappos, Earthquake resistant concrete structures, (Thompson Press Ltd, Madras, India, 2005) 51-52.

[3]. Bilham, R., The seismic future of cities. Bulletin of Earthquake Engineering, 7(4), 2008, 839-887.

[4]. Nanni, A. and N. M. Bradford (1995). FRP jacketed concrete under uniaxial compression. Construction and Building Materials, 9(2), 1995, 115-124.

[5]. Ozbakkaloglu, T. and M. Saatcioglu, Seismic behavior of high-strength concrete columns confined by fiber-reinforced polymer tubes. Journal of composites for construction, 10(6), 2006, 538-54

[6]. Niroomandi, A., A., Maheri, M. R. Maheri, S. S. Mahini, Seismic performance of ordinary RC frames retrofitted at joints by FRP sheets, Engineering Structures, 32(8), 2010, 23262336.

[7]. Pellegrino, C. and C. Modena, Analytical model for FRP confinement of concrete columns with and without internal steel reinforcement, Journal of composites for construction 14(6), 2010, 693-705.

[8]. Li, G., S. S., Pang, S. I. Ibekwe, FRP tube encased rubberized concrete cylinders, Materials and structures 44(1), 2011, 233243.

[9]. Youssf, O., M. A. ElGawady, J. E. Mills, X. $\mathrm{Ma}$, An experimental investigation of crumb rubber concrete confined by fibre reinforced polymer tubes, Construction and Building Materials 53, 2014, 522-532.

[10]. Erik, A. J., J. C. Ramallo, B. F. Spencer Jr and M. K. Sain, Intelligent base isolated systems, Second World Conference on structural Control, Kyoto Japan, 1998.

[11]. Farzad N. and Kelly M. J., Design of seismic isolated structures: from theory to practice. (Library of Congress, 1999).

[12]. Xue, J. and M. Shinozuka, Rubberized concrete: a green structural material with enhanced energy-dissipation capability. Construction and Building Materials 42, 2013, 196-204.

[13]. Samar R and K. Pilakoutas, upublished experimental data on rubberised concrete at the department of civil and structural engineering, University of Sheffield, United kingdom, 